Research Article

\title{
Genetic variation among species, races, forms and inbred lines of lac insects belonging to the genus Kerria (Homoptera, Tachardiidae)
}

\author{
Sanjeev Kumar Ranjan ${ }^{1}$, Chandana Basu Mallick ${ }^{1}$, Dipnarayan Saha ${ }^{2}$, Ambarish S Vidyarthi ${ }^{3}$ \\ and Ranganathan Ramani ${ }^{1}$ \\ ${ }^{1}$ Lac Production Division, Indian Institute of Natural Resins and Gums, Indian Council of Agricultural \\ Research, Ranchi, India. \\ ${ }^{2}$ National Bureau of Plant Genetic Resources, New Delhi, India. \\ ${ }^{3}$ Department of Biotechnology, Birla Institute of Technology, Mesra, India.
}

\begin{abstract}
The lac insects (Homoptera: Tachardiidae), belonging to the genus Kerria, are commercially exploited for the production of lac. Kerria lacca is the most commonly used species in India. RAPD markers were used for assessing genetic variation in forty-eight lines of Kerria, especially among geographic races, infrasubspecific forms, cultivated lines, inbred lines, etc., of $K$. lacca. In the 48 lines studied, the 26 RAPD primers generated 173 loci, showing $97.7 \%$ polymorphism. By using neighbor-joining, the dendrogram generated from the similarity matrix resolved the lines into basically two clusters and outgroups. The major cluster, comprising 32 lines, included mainly cultivated lines of the rangeeni form, geographic races and inbred lines of $K$. lacca. The second cluster consisted of eight lines of $K$. lacca, seven of the kusmi form and one of the rangeeni from the southern state of Karnataka. The remaining eight lines formed a series of outgroups, this including a group of three yellow mutant lines of $K$. lacca and other species of the Kerria studied, among others. Color mutants always showed distinctive banding patterns compared to their wild-type counterparts from the same population. This study also adds support to the current status of kusmi and rangeeni, as infraspecific forms of $K$. lacca.
\end{abstract}

Key words: DNA fingerprinting, genetic variation, Kerria, lac insects, RAPD, Tachardiidae.

Received: February 7, 2011; Accepted: May 4, 2011.

\section{Introduction}

The lac insects (Coccoidea: Tachardiidae (= Kerriidae)) have been commercially harnessed to yield three useful products, viz., resin, wax and dye, which have found a remarkably wide range of applications in food, pharmaceuticals, cosmetics, perfumes, varnishes, paints, polishes, adhesives, jewellery and textile dyes, since ancient times (Dave, 1950; Sarkar, 2002; Ramani et al., 2007). Lac is the only resin of animal origin. The importance of this commodity lies in its safety for human use, and as a renewable and eco-friendly resource. Lac production is confined to a few south, southeast and east Asian countries in the tropical forest region (Ramani et al., 2007) with India is the leading lac-producer, with an annual production of about twenty thousand tons (Pal et al., 2011). Lac insects are characterized by their resinous or horny protective secretion. They are phytosuccivorous and sessile; only the crawlers and adult males are free moving. They thrive well only on certain plant species known as lac hosts (Kapur,

Send correspondence to Ranganathan Ramani. Indian Institute of Natural Resins and Gums, Ranchi 834010 Jharkhand, India. E-mail: ramani_9@scientist.com.
1962; Varshney, 1985). Information on the taxonomy of lac insects is based on a monograph and its supplement (Chamberlin 1923, 1925), as well as subsequent works by Kapur (1958), Varshney (1977) and Kondo and Gullan (2007). Ninety species, under nine genera, have so far been reported worldwide (Varshney, 2009). Distribution is mainly restricted to tropical and subtropical regions between the latitudes $40^{\circ} \mathrm{N}$ and $40^{\circ} \mathrm{S}$ (Kapur, 1962).

Only species belonging to the genus Kerria produce true lac. In India, nearly all the production comes from the Indian lac insect Kerria lacca, represented by two infrasubspecific forms, viz., kusmi and rangeeni, which differ by host preference, life-cycle pattern, the quality and amount of lac produced, etc. (Kapur, 1962; Ramani, 2005). Other minor species are K. sharda (Mishra and Sushil, 2000) and K. chinensis. Palas (Butea monosperma), ber (Ziziphus mauritiana) and kusum (Schleichera oleosa) are the most common hosts used for lac production in India (Roonwal 1962), which is mainly restricted to the states of Jharkhand, Chhattisgarh, Madhya Pradesh, West Bengal, Maharashtra, besides a few others (Pal et al., 2011). Notwithstanding, wild populations of Kerria are distributed 
throughout the length and breadth of the country, except in the colder regions (Varshney 1977).

The taxonomy of coccoids is based on adult-female morphology (Varshney, 1977; Kondo and Gullan, 2007). Even so, they are highly degenerate, and undergo tremendous changes in size and shape during the post-metamorphic stage. Differentiated populations, due to geographic separation and host-choice, and which have not diverged morphologically, pose an additional challenge to identification. Molecular approaches would therefore serve as useful complementary tools for characterizing such lac-insect taxa with greater reliability. A wide range of markers are employed for understanding insect-population genetics (Behura, 2006). RAPD-PCR is widely used for identifying cultivars, clones, natural populations, etc. Despite the limitation posed by reproducibility, unless reaction conditions are stringent (Baruffi et al.,1995 and Bertin et al., 2007), this technique offers the advantages of simplicity, independence from prior DNA sequence information, and the evaluation of a large number of loci across the genome (Hadrys et al., 1992; Lynch and Milligan, 1994; Weising et al., 2005), besides providing the basis for developing more reliable SCAR (sequence characterized amplified regions) markers (Kethidi et al., 2003). The technique has already been widely employed for assessing the genetic diversity of other insect populations (Reyes and Ochando, 1998; Castiglioni and Bicudo, 2005; Dvorak et al., 2006; Lopes-DaSilva and Vieira, 2007; Martins et al., 2007; Magaña et al., 2007; Karam et al., 2007; Sosa-Gomez et al., 2008; Sharma et al., 2009).
This constitutes a report on genetic diversity in lacinsect populations belonging to the genus Kerria, the true lac-producing insects, from different parts of India, using the RAPD technique (Williams et al., 1990; Welsh and McClelland, 1990). The study material included lac-insect populations collected from different parts of the country, both natural and cultured populations, besides inbred lines derived from $K$. lacca. The usefulness of RAPD primers for line-characterization is also examined. An attempt was also made to understand relationships among the lines studied.

\section{Material and Methods}

\section{Lac-insect collection and culture}

The insects used in the study were obtained from lac-insect cultures maintained at the Research Farm,

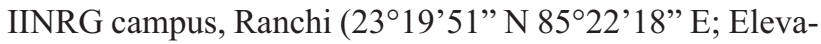
tion $\sim 2080 \mathrm{ft}$ ). A few were also drawn from collections of natural field populations (Table 1; Figure 1). The lac-insect cultures were maintained on a common lac host Flemingia macrophylla, under potted conditions. The cultures, enclosed in synthetic mesh sleeves to exclude parasite and predator infestation, were regularly sprayed with fungicide (carbendazim, $0.01 \%$ ) to maintain cleanness. Fieldcollected insects were carefully screened, in order to select only healthy ones. The lines studied mainly included the most commonly used species for lac production, viz., $K$. lacca (kusmi and rangeeni infrasubspecific forms), a collection of $K$. sharda, and two collections of $K$. chinensis (India and Thailand), as well as inbred and crossbred lines,

Table 1 - Details of the 48 lines of Kerria studied, including coding and place of collection.

\begin{tabular}{lccl}
\hline Group/Nature & Number used to indicate the location on the map & Code No. & Place of collection \\
\hline $\begin{array}{l}\text { I } \text { K. lacca, cultivated lines } \\
\text { Rangeeni }\end{array}$ & 1 & & \\
& 2 & LI003 & Silli, Jharkhand \\
& 3 & LI011 & Ranchi, Jharkhand \\
& 3 & LI019A & Bokaro, Jharkhand, yellow \\
& 4 & LI019B & Bokaro, Jharkhand, crimson \\
& 5 & LI032 & Kirnapur, Madhya Pradesh* \\
& 6 & LI042 & Mainpur, Chhattisgarh* \\
& 7 & LI044 & Jhalda, West Bengal* \\
Kusmi & 8 & LI048 & Kalamati, Jharkhand \\
& 9 & LI087 & Vardha (Guna), Madhya Pradesh \\
\hline 10 & LI005 & Ranchi, Jharkhand \\
& 12 & LI012 & Purulia, West Bengal \\
& 13 & LI025 & Putidih, West Bengal \\
& 14 & LI026 & Chandai, West Bengal \\
\hline 15 & LI027 & Nawadih, Jharkhand \\
& 16 & LI028 & Kulajanga, West Bengal
\end{tabular}


Table 1 (cont.)

\begin{tabular}{|c|c|c|c|}
\hline Group/Nature & Number used to indicate the location on the map & Code No. & Place of collection \\
\hline & 17 & LI077 & Hesadih, Jharkhand \\
\hline \multicolumn{4}{|l|}{ II $K$. lacca, geographic races } \\
\hline Northern & 18 & LI072B & Varanasi, Uttar Pradesh* \\
\hline Northern & 19 & LI073 & Bhathat, Uttar Pradesh \\
\hline Eastern & 20 & LI029 & Ashok Nagar, Ranchi, Jharkhand \\
\hline Eastern & 21 & LI031 & Rajendra Chowk, Ranchi, Jharkhand \\
\hline Eastern & 22 & LI078 & Orissa, kusmi yellow \\
\hline Western & 23 & LI004 & Simbalpani, Gujarat \\
\hline Western & 24 & LI018 & Manasarovar, Gujarat \\
\hline Western & 25 & LI006 & Pushkar, Rajasthan \\
\hline Western & 26 & LI069 & Chargaon, Maharashtra* \\
\hline Western & 27 & LI015 & Simbalpani, Gujarat, yellow \\
\hline Western & 28 & LI013 & Alsipur, Gujarat, yellow \\
\hline Central & 29 & LI085 & Guna, Madhya Pradesh* \\
\hline Southern & 30 & LI009A & Thrissur, Kerala, yellow \\
\hline Southern & 30 & LI009B & Thrissur, Kerala, crimson \\
\hline Southern & 31 & LI079 & Bangalore, Karnataka \\
\hline Southern & 32 & LI082 & Vishakapatnam, Andhra Pradesh* \\
\hline Southern & 33 & LI010RR & Echoda, Andhra Pradesh \\
\hline \multicolumn{4}{|l|}{ III $K$. lacca, experimental lines } \\
\hline Inbred line 3 , & - & LI007 & Kundri, Jharkhand \\
\hline Inbred line 8 & - & LI008 & Kundri, Jharkhand \\
\hline Inbred line 1 & - & LI014 & Kundri, Jharkhand \\
\hline Inbred line 6 & - & LI020 & Kundri, Jharkhand \\
\hline Inbred line 9 & - & LI022 & Kundri, Jharkhand \\
\hline Inbred line 13 & - & LI024 & Kundri, Jharkhand \\
\hline Crossbred line $1(13 \mathrm{f} \times 8 \mathrm{~m})$ & - & LI058 & Kundri, Jharkhand \\
\hline Crossbred line $2(13 \mathrm{f} \times 3 \mathrm{~m})$ & - & LI061 & Kundri, Jharkhand \\
\hline $\begin{array}{l}\text { Cream line, recombi- } \\
\text { nant, crimson }\end{array}$ & - & LI001B & Kundri, Jharkhand \\
\hline $\begin{array}{l}\text { Cream line, recombi- } \\
\text { nant, cream }\end{array}$ & - & LI001A & Kundri, Jharkhand \\
\hline \multicolumn{4}{|l|}{ IV other species } \\
\hline K. chinensis & 33 & LI002 & Nangpoh, Meghalaya, India \\
\hline K. sharda & 34 & LI066 & Sarat, Orissa \\
\hline K. chinensis & - & LI068 & Thailand \\
\hline
\end{tabular}

* Field collected. The exact locations of certain collections are unavailable.

and collections from wild populations collected from all over of India. These lines were divided into four groups, depending on the nature (Table 1).

\section{Insect processing and DNA isolation}

Mature female insects were kept in $100 \%$ ethanol for $48 \mathrm{~h}$ at room temperature, so as to dissolve the resinous covering, whence they were individually cleaned with sable-hair brushes under a stereo-zoom microscope, and serially washed with alcohol to eliminate waxy secretions. The cleaned insects were kept in $200 \mu \mathrm{L}$ absolute ethanol in $1.5 \mathrm{~mL}$ microcentrifuge tubes and stored in $-80{ }^{\circ} \mathrm{C}$ freezer. DNA was extracted from mature females, adopting a phenol-chloroform procedure described by De Barro et al. (1995), with some modifications. The extracted DNA was individually quantified with a Shimadzu UV-VIS 1700 spectrophotometer using a DNA program pack, and checked by electrophoresis on $1 \%$ agrose gel together with 100 bp DNA ladder-plus (Fermentas, Germany). 


\section{RAPD amplification and gel electrophoresis}

We screened 120 decamer primers (Operon Biotechnologies $\mathrm{GmbH}$, Germany) for satisfactory amplification of products, using three selected lines. RAPD-PCR was carried out with 48 samples of pooled genomic DNA from three female insects, to shortlist primers exhibiting polymorphism and reproducibility. For each of these primers, annealing temperatures and other parameters were standardized by repeated experiments (Table 2). All the RAPD reactions were done in $25 \mu \mathrm{L}$ of reaction mixtures containing $20 \mathrm{ng}$ of template DNA, 1X Taq buffer [ $750 \mathrm{mM}$ Tris- $\mathrm{HCl}(\mathrm{pH} 8.8), 200 \mathrm{mM}\left(\mathrm{NH}_{4}\right)_{2} \mathrm{SO}_{4}, 0.1 \%$ (v/v) Tween 20; Fermentas $\mathrm{GmbH}$, Germany], $2.5 \mathrm{mM}$ of $\mathrm{MgCl}_{2}$ (Fermentas GmbH, Germany), $0.2 \mathrm{mM}$ of each dNTP mix (Fermentas GmbH, Germany), 20 pmol of each primer, and 1.5 units of Taq DNA polymerase (Fermentas GmbH, Germany). All the PCR reactions were carried out in a thermal cycler (BioRad iCycler, USA) programmed with the following cycling conditions: initial denaturation of template DNA was carried out at $95^{\circ} \mathrm{C}$ for $5 \mathrm{~min}$ followed by $35 \mathrm{cy}$ cles programmed for denaturation step at $95{ }^{\circ} \mathrm{C}$ for $1 \mathrm{~min}$,

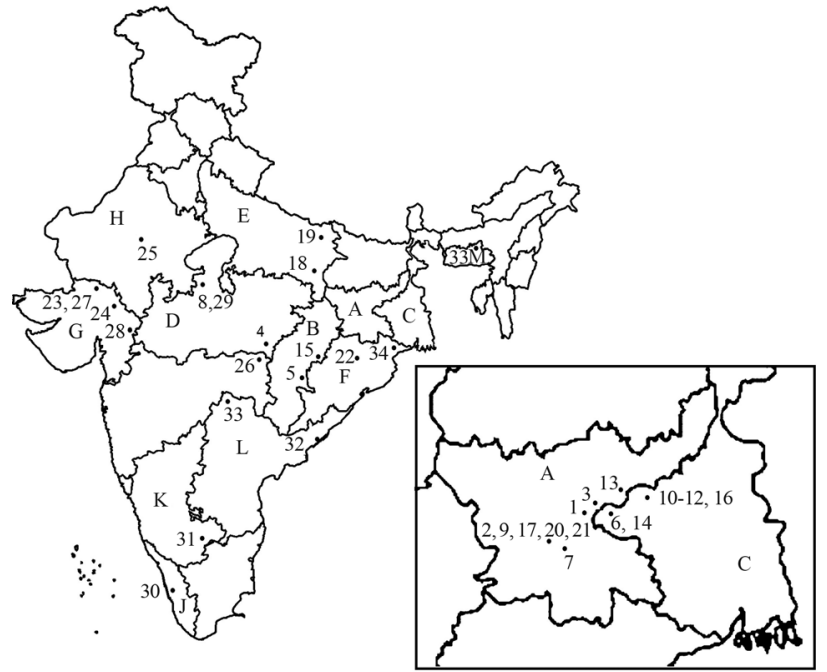

Figure 1 - Map of India, showing State boundaries, collection sites of the cultivated lines, and geographic races of $K$. lacca and other species of Kerria studied (A: Jharkhand, B: Chhattisgarh, C: West Bengal, D: Madhya Pradesh, E: Uttar Pradesh, F: Orissa, G: Gujarat, H: Rajasthan, I: Maharshtra, J: Kerala, K: Karnataka, L: Andhra Pradesh, M: Meghalaya). Inset - the states of Jharkhand and West Bengal.

Table 2 - The list of primers used, their sequences, $T_{m}$, number of bands generated, size-range and degree of polymorphism.

\begin{tabular}{|c|c|c|c|c|c|}
\hline Primers & Primer sequence $\left(5^{\prime}-3^{\prime}\right)$ & $\mathrm{T}_{\mathrm{m}}\left({ }^{\circ} \mathrm{C}\right)$ & Total number of scored bands & Band-size range (bp) & No. of polymorphic bands (\%) \\
\hline OPS9 & TCCTGGTCCC & 42 & 3 & $200-1000$ & $2(66.6 \%)$ \\
\hline OPS10 & ACCGTTCCAG & 42 & 7 & $200-1500$ & $6(85.7 \%)$ \\
\hline OPS12 & CTGGGTGAGT & 42 & 1 & 600 & $1(100 \%)$ \\
\hline OPS13 & GTCGTTCCTG & 42 & 10 & $300-1200$ & $10(100 \%)$ \\
\hline OPS14 & AAAGGGGTCC & 42 & 6 & $400-1850$ & $6(100 \%)$ \\
\hline OPS15 & CAGTTCACGG & 42 & 4 & $600-1500$ & $4(100 \%)$ \\
\hline OPS16 & AGGGGGTTCC & 42 & 1 & 700 & $1(100 \%)$ \\
\hline OPS17 & TGGGGACCAC & 42 & 7 & $600-1500$ & $7(100 \%)$ \\
\hline OPS19 & GAGTCAGCAG & 42 & 12 & $300-1200$ & $11(91.7 \%)$ \\
\hline OPS20 & TCTGGACGGA & 42 & 8 & $500-2000$ & $8(100 \%)$ \\
\hline OPT5 & GGGTTTGGCA & 37 & 10 & $200-1000$ & $10(100 \%)$ \\
\hline OPT7 & GGCAGGCTG & 37 & 11 & $400-1600$ & $11(100 \%)$ \\
\hline OPT15 & GGATGCCACT & 37 & 8 & $200-950$ & $8(100 \%)$ \\
\hline OPT16 & GGTGAACGCT & 37 & 10 & $300-1700$ & $9(90 \%)$ \\
\hline OPH5 & AGTCGTCCCC & 37 & 10 & $450-2000$ & $10(100 \%)$ \\
\hline OPH9 & TGTAGCTGGG & 37 & 5 & $400-1300$ & $5(100 \%)$ \\
\hline OPH12 & ACGCGCATGT & 37 & 9 & $400-1300$ & $9(100 \%)$ \\
\hline OPH19 & CTGACCAGCC & 37 & 10 & $600-1900$ & $10(100 \%)$ \\
\hline OPB4 & GGACTGGAGT & 37 & 4 & $600-1400$ & $4(100 \%)$ \\
\hline OPB15 & GGAGGGTGTT & 37 & 4 & $600-1600$ & $4(100 \%)$ \\
\hline OPB18 & CCACAGCAGT & 37 & 4 & $600-1300$ & $4(100 \%)$ \\
\hline OPA2 & TGCCGAGCTG & 42 & 8 & $300-1500$ & $8(100 \%)$ \\
\hline OPA10 & GTGATCGCAG & 42.5 & 3 & $800-1600$ & $3(100 \%)$ \\
\hline OPA9 & GGGTAACGCC & 42 & 7 & $600-1250$ & $7(100 \%)$ \\
\hline OPA18 & AGGTGACCGT & 42.5 & 4 & $350-1200$ & $4(100 \%)$ \\
\hline OPA13 & CAGCACCCAC & 42 & 7 & $400-1400$ & $7(100 \%)$ \\
\hline
\end{tabular}


primer annealing step at specific $\mathrm{T}_{\mathrm{m}}$ for the particular primer (Table 2) for $45 \mathrm{~s}$, and extension step at $72{ }^{\circ} \mathrm{C}$ for $2 \mathrm{~min}$. The final extension of the PCR products was carried out at $72{ }^{\circ} \mathrm{C}$ for $7 \mathrm{~min}$. The reactions were carried out as described by Williams et al. (1990) and Nagaraja and Nagaraju (1995). All PCR amplified products were resolved on $2 \%$ agarose gel containing $0.5 \mu \mathrm{g} / \mathrm{mL}$, ethidium bromide, prepared with $0.5 \mathrm{X}$ TBE buffer $[45 \mathrm{mM}$ Tris-borate, $1.0 \mathrm{mM}$ EDTA ( $\mathrm{pH} \mathrm{8.0)]} \mathrm{and} \mathrm{electrophoresed} \mathrm{in} 0.5 \mathrm{X}$ TBE at $4 \mathrm{~V} \mathrm{~cm}^{-1}$ for $2 \mathrm{~h}$ in an Amersham submarine electrophoresis unit. Either Fermentas 100 bp ladder (100-1000) or $100 \mathrm{bp}$ plus ladder (100-3000) were used as reference, depending on the band-size range. Sufficiently resolved DNA bands were documented using the Bioimaging system (Gene Genius, Syngene, U K), through GeneSnap.

\section{Data analysis}

Clear and unambiguous bands present across the DNA samples from 48 lac-insect lines at a particular locus (based on size) were scored as 1 , whereas their absence or only a very faint outline were scored as 0 , to so generate a binary matrix, to be used for analysis.

For line diagnosis and the analysis of marker discrimination power, the average band frequency obtained for each primer, marker index (MI) and resolving power (Rp), using band informativeness (Ib), were calculated (Prevost and Wilkinson 1999).

$$
\mathrm{Ib}=1-(2|0.5-\mathrm{pi}|)
$$

where pi is the proportion of lines showing the $\mathrm{i}^{\text {th }}$ band, and $\mathrm{i}=1$ to $\mathrm{n}$ where ' $\mathrm{n}$ ' is the total number of bands.

Primer resolving power ( $\mathrm{Rp}$ ) was also calculated using the following formula

$$
\mathrm{Rp}=\Sigma \mathrm{Ib}
$$

where Ib is band informativeness, as calculated above.

Marker index (MI) is the parameter for determining the utility of the marker in distinguishing different genotypes. The estimation of MI was by applying the following formula provided by Archak et al. (2003), based on band informativeness, as computed above.

$$
\mathrm{MI}=1 / \mathrm{n} \mathrm{Ib} \times \mathrm{EMR}
$$

where EMR (effective multiplex ratio) is the product of the number of polymorphic bands (i.e. a band absent in at least one genotype at a particular locus) per primer and the fraction of polymorphic bands.

In order to study the genetic relationships among Kerria lines, the scored binary data matrix was analyzed using the NTSYSpc version 2.02e software program (Exeter Software, New York, USA) (Rohlf, 1998). Data analysis was to obtain Jaccard's similarity coefficient. The dendrogram was generated by applying the neighbor-joining method (Saitou and Nei, 1987), using midpoint rooting. Only wild-type insects were considered for assessing the variation of similarity indices, in the case of mixed populations. The same software was used for principal coordinate (PCOORD) analysis (Sneath and Sokal, 1973) of the data. The confidence level for distinguishing genotypes, using the selected primers, was estimated through the analysis of probability of identical match by chance $\left(P_{i m c}\right)$, as proposed by Wetton et al. (1987) and Ramakishana et al. (1994).

$$
P_{i m c}=(\text { Mean the Jaccard similarity index })^{\mathrm{n}}
$$

where ' $n$ ' is the mean number of bands amplified per line.

\section{Results and Discussion}

Out of the 120 RAPD primers screened, 26 produced the satisfactory, clear and reproducible banding patterns used herein. These produced 173 loci in the 48 lines studied, of which 169 (97.7\%) were found to be polymorphic. The size of the amplified products varied between $\sim 200 \mathrm{bp}$ and $2.0 \mathrm{kbp}$. The maximum size-range of amplified products for a single primer was obtained with OPH5 (450-2.0 kbp), whereas the minimum, i.e., one single band (600 bp), was obtained with OPS12. The number of bands produced by the primers ranged from 1 (OPS 12 and OPS 16) to 12 (OPS 19), with an average of 6.7 per primer. Polymorphism in the bands produced by all the RAPD primers, except for OPS 9, OPS 10, OPS 19 and OPT 16, was 100\%. The least was obtained with OPS9 $(66.6 \%)$. The primers used, their sequences, $T_{m}$, number of scored bands, bandsize range and the number of polymorphic bands, are given in Table 2. The total number of amplified bands in all the forty-eight lac-insect lines generated, when using all the twenty-six RAPD primers, was 3,380, with an average of 70.4 bands per line. The number of bands amplified through all the primers in all the lines ranged from 33 (LI036) to 95 (LI025).

The resolving power $(\mathrm{Rp})$ of the primers screened ranged from 0.08 (OPS9) to 4.08 (OPA13), with a mean of 1.97. The lowest MI value was observed with OPS9 and the highest with OPS19. The mean MI of the primers was 1.82.

A total 33 unique bands were generated, with 15 RAPD primers (OPS9, OPS10, OPS13, OPS15, OPS17, OPS19, OPT7, OPT16, OPH5, OPH12, OPH19, OPB15, OPB18, OPA2 and OPA9) in eight lac-insect lines (LI002, LI010RR, LI09B, LI068, LI05, LI044, LI087 and LI069). The highest number of unique bands (21 out of 33), compared to the remainder, was in Line LI002, Kerria chinensis from India. Only three (LI002, LI003 and LI015) presented unique null bands with four RAPD primers, OPT16, OPS19, OPS10 and OPS9. In line LI003, there was a unique null band with three primers, viz., OPS19, OPS10 and OPS9. Out of the 48 lac-insect lines analyzed, nine, viz., LI009A, LI002, LI068, LI043, LI085, LI026, LI027, LI003 and LI028, could be identified by the presence of two bands by eight primers. With most of the primers, lines LI002 and LI068, K. chinensis lines, respectively from In- 
dia and Thailand, were found to share a common pattern, by the presence or absence of two bands.

Pair-wise Jaccard's similarity indices varied from 0.15 (LI068, LI003) to 0.81 (LI012, LI015; LI029, LI032; LI048, LI032), with a mean of 0.58 for all the cultivated lines, geographic races of $K$. lacca and two other species (Groups I, II and IV in Table 1). The index varied between 0.27 (LI036, LI085) and 0.81 among the 33 cultivated lines and geographic races of $K$. lacca (Groups I and II in Table 1 ), with a mean of 0.61 , indicative of significant intraspecific genetic diversity. The six inbred lines of $K$. lacca (rangeeni), derived from a single mother population, presented divergence with a mean similarity index of 0.77 (range: 0.62-0.92). Analysis of the above data showed that the probability of identical chance matching was $4.74 \times 10^{-16}$, thus indicative of a high level of reliability.

The dendrogram generated from the Jaccard's similarity matrix, by using the neighbor-joining method, appears in Figure 2. Basically, it resolves the lines into two major clusters (nodes A and B), as well as outgroups comprising eight lines under six branches (1 to 6). The cluster originating from node $\mathrm{A}$, the major one comprising 32 lines, basically includes cultivated lines of the rangeeni form, geographic races and inbred lines of $K$. lacca. It is further differentiated into three subclusters (A1, A2 and A3). Subcluster A1 is a heterogeneous group of seven lines, comprised of two (LI003 and LI031) from Jharkhand State, two (LI42 and LI36) from Chhattisgarh State, two from Andhra Pradesh State, and a cream recombinant mutant line (LI001A). The subcluster from node A2 is comprised of 15 lines, mainly from the eastern region, and consists of six lines derived from cultivated populations of four adjoining lac-growing states (Jharkhand, West Bengal, Chhattisgarh and Madhya Pradesh), six inbred lines (also developed from a cultivated population from Jharkhand), two geographic races from northern and eastern India, and the wild-type color form of a recombinant line (LI001B). The subcluster of ten lines originating from A3, is mainly composed of those from western India (five from Gujarat and Rajasthan), one from the northern state of Uttar Pradesh (LI72B), two crossbred lines (LI058 and LI061), and the yellow mutant of a kusmi line from Orissa (LI078), whereas subclusters A2 and A3 mainly consist of lines from eastern and western regions of India, respectively.

Node B comprises eight lines, viz., seven of the kusmi form and one of the rangeeni of $K$. lacca from the southern state of Karnataka. These forms of $K$. lacca appear to have originated through a common ancestor at O. Kusmi insects are naturally distributed mainly in the eastern part of peninsular India, whereas the rangeeni are distributed countrywide. These two forms differ as to host preference rangeeni insects are characterized by their ability to thrive well on Butea monosperma, and kusmi on Schleichera oleosa (Varshney, 1977). Based on crosses between the two, it has been shown that the kusmi form is genetically

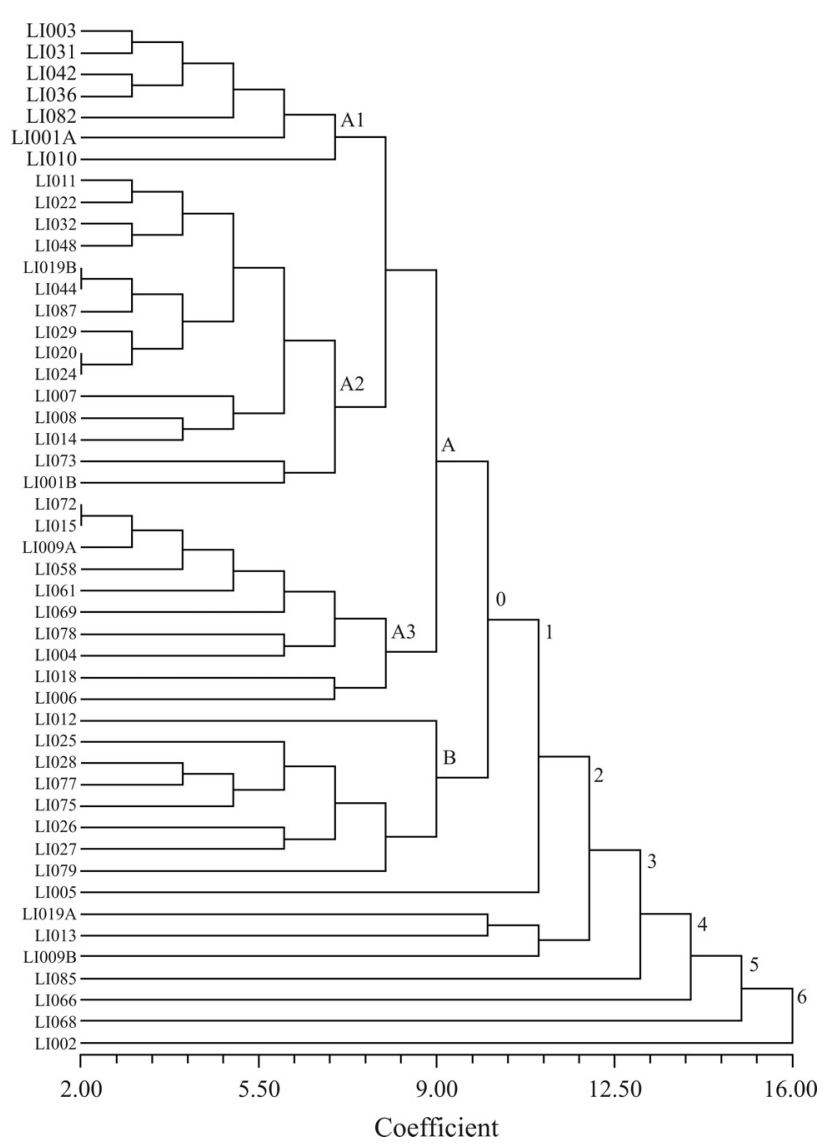

Figure 2 - Dendrogram showing phenetic relationship of 48 lines of Kerria, generated from Jaccard's similarity coefficients, based on RAPD data, and using the neighbour-joining method.

endowed for survival on S. oleosa (Chauhan and Mishra, 1970). This form of the Indian lac insect probably originated through host-shift. The remaining eight lines form a series of outgroups (branches 1-6), which include one of the kusmi form (LI005), one collection from the central state of Madhya Pradesh (LI085), and a group of three yellow mutant lines (9B, 19A and 13) of $K$. lacca, besides two lines of $K$. chinensis (LI068 and LI002) and one of K. sharda.

The dendrogram differentiated the species of Kerria studied, as well as LI085, represented as an outgroup, and which requires re-examination as to taxonomic status. Three color mutants in K. lacca (white, yellow and cream), which affect body and resin color, have been shown to be recessive (Chauhan, 1977; Chauhan and Mishra, 1977; Ramani, 2002). In the present study, the dendrogram generated always separated colour mutants (yellow and cream) from their wild-type counterparts in the same population, due to their distinctive RAPD banding profiles, indicative of their distinct genetic makeup.

Principal component analysis revealed that $27.2 \%$ of the variation could be attributed to the first three components. Figure 3 presents the $3-\mathrm{D}$ plot of the principal coordinate analysis of the similarity matrix data of the lines studied. The K. lacca populations are well-spread over the 


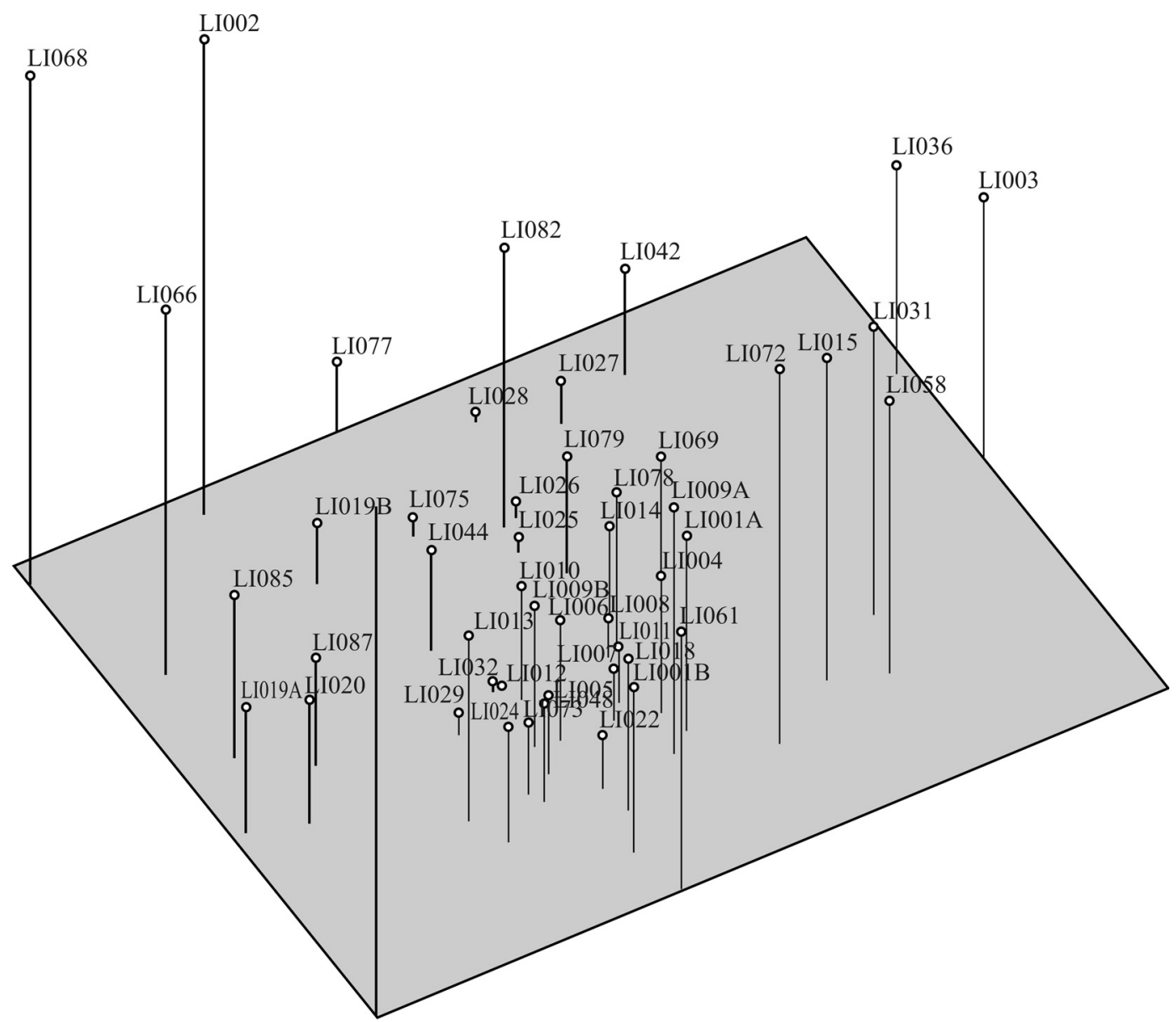

Figure 3 - 3-D plot generated from principal coordinate analysis of RAPD similarity matrix data from the forty-eight lines of Kerria.

dimensions, thereby indicating their diversity. Two lines of $K$. chinensis derived from different geographic locations (LI002 and LI068), as well as K. sharda (LI066), are well separated from those of $K$. lacca, thus consistent with the NJ dendrogram. According to PCOORD analysis, the seven kusmi lines of $K$. lacca, which formed a group at node $\mathrm{B}$ in this dendrogram, appeared to spread out. The lines LI075 (Kalamati, West Bengal) and LI077 (Hesadih, Jharkhand) appeared distinct. It is worth mentioning that spurious emergence was reported in the line from LI077. Spurious larval emergence, a phenomenon whereby some crawler emergence takes place during a non-typical period (Nov-Dec) in kusmi populations, is indicative of interbreeding in kusmi and rangeeni forms. Oviposition peaks in the segregating progenies of crosses of these two forms correspond to the parental types. Four lines of the rangeeni form of K. lacca, LI19A \&B, LI020, LI085 and LI087, tended to form a cluster at variance with the dendrogram. These populations were from Jharkhand and Madhya Pradesh.

Lac insects, by depending on perennial trees for survival, are specialists in the preference for host-plants with limited dispersal. They may thus become locally adapted, thereby forming genetically distinct geographic and host races without morphological differentiation. Human intervention, with systematic lac-cultivation and the transport of insect populations across various regions, also exerts an influence on dispersal and interpopulation gene flow. Thus, divergence in $K$. lacca,can be expected, through being both the most commonly used species for lac-production and widely distributed in India. The above findings corroborate population divergence through geographic isolation and differences in host preference. The results also indicated that populations from geographically adjoining areas tend to be similar. Intermixing of cultivated populations is also expected in lac-producing areas, due to the transportation of insects within the cultivated areas, discernible in lineclustering in node A2 from the principal lac growing region. The six inbred lines derived from the same mother population also diverged from each other, with only LI024 and LI020 remaining similar.

The two forms of Kerria lacca, kusmi and rangeeni, commonly referred to as 'strains' in lac-insect literature, are distinct as regards certain commercial and biological traits. Based upon morphological characteristics, they were allocated as infrasubspecific forms by Varshney (1977). Mishra et al. (1998) recorded the mutual morphometric differences. Even so, they hybridize freely under laboratory 
conditions, thereby producing viable progeny. Premating barriers, such as differences in host preference and asynchrony in sexual-maturity periods, due to differences in life-cycle patterns, prevent interbreeding under natural conditions. Nevertheless, through occasional periodoverlaps during the rainy-season generation of both forms, interbreeding is possible. A probable illustration is a subgroup of the A1 node cluster, comprising two collections from geographically close locations, i.e., LI042, a line of the rangeeni form, collected from Mainpur, Chhattisgarh, and LI036 a line of the kusmi form from Kurubhatta, also Chhattisgarh. Spurious crawler emergence in LI077, indicative of interbreeding in these two forms, has already been discussed.

The usefulness of RAPD-PCR for assessing genetic diversity in Indian lac insects has been demonstrated. Considering the general recommendation of fifty polymorphic markers to establish precise genetic distances (Nei, 1978), 26 RAPD primers having produced 169 polymorphic bands is sufficient for distinguishing species to complement pertinent taxonomic studies. Some of these can even be used for characterizing populations at the intraspecific level. The dendrogram generated from the similarity matrix also throws light on the interrelationships of the OTUs investigated. The above molecular evidence supports the current status of kusmi and rangeeni, as infraspecific forms of $K$. lacca. These forms appear to have descended from a common ancestor. Color mutants also need to be examined in greater detail, in order to understand the basis for their differentiation. Based on RAPD profiles, the lac-insect populations of $K$. lacca collected from different locales presented considerable variation. Further studies using other markers and DNA sequence variation, are likely to throw fresh light on these populations and their respective relationships.

\section{Acknowledgments}

The authors wish to thank the Director, IINRG, for support in carrying out the research work, Mr. A.K. Sinha for his help in collecting and culturing lac insect populations, and Shri Bhupal Kumar for technical assistance, as well as the anonymous reviewers for their valuable and critical reviewing of the article. Financial support for the work under this project was rendered by the Department of Biotechnology, Government of India.

\section{References}

Archak S, Gaikwad AB, Gautam D, Rao EVVB, Swamy KRM and Karihaloo JL (2003) Comparative assessment of DNA fingerprinting techniques (RAPD, ISSR and AFLP) for genetic analysis of cashew (Anacardium occidentale L.) accessions of India. Genome 46:362-369.

Baruffi L, Damiani G, Guglielmino CR, Bandi C, Malcrida AR and Gasperi G (1995) Polymorphism within and between populations of Ceratitis capitata: Comparison between
RAPD and multilocus enzyme electrophoresis data. Heredity $74: 425-437$.

Behura SK (2006) Molecular marker systems in insects: Current trends and future avenues. Mol Ecol 15:3087-3113.

Bertin S, Guglielmino CR, Karam N, Gomulski ML, Malacrida AR and Gasperi G (2007) Diffusion of the Nearctic leafhopper Scaphoideus titanus Ball in Europe: A consequence of human trading activity. Genetica 131:275-285.

Castiglioni L and Bicudo HEMC (2005) Molecular characterization and relatedness of Haematobia irritans (horn fly) populations, by RAPD-PCR. Genetica 124:11-21.

Chamberlin JC (1923) A systematic monograph of the Tachardiinae or lac insects (Coccidae). Bull Entomol Res 14:147-212

Chamberlin JC (1925) Supplement to a monograph on the Lacciferidae (Tachardiinae) or lac insects (Homoptera, Coccidae). Bull Entomol Res 16:31-41.

Chauhan NS (1977) Gene expression and transmission in Kerria lacca (Kerr). Heredity 38:755-759.

Chauhan NS and Mishra YD (1970) Genetic evidence of nutritional differences in lac insects. Indian $\mathrm{J}$ Entomol 32:390-391

Chauhan NS and Mishra YD (1977) White: A new colour locus in Kerria lacca (Kerr) Curr Sci 46:272-273.

Dave KN (1950) Lac and the Lac Insect in the Atharva-Veda. International Academy of Indian Culture, Nagpur, 16 pp.

De Barro PJ, Sherratt TN, Brookes CP, David O and Maclean N (1995) Spatial and temporal genetic variation in British field populations of the grain aphid Sitobion avenae (F.) (Hemiptera, Aphididae) studied using RAPD-PCR. Proc R Soc Lond Ser B Biol Sci 262:321-327.

Dvorak V, Aytekin AM, Alten B, Skarupova S, Votypka J and Volf P (2006) A comparison of the intraspecific variability of Phlebotomus sergenti Parrot, 1917 (Diptera, Psychodidae). J Vector Ecol 31:229-238.

Hadrys H, Balick M and Schierwater B (1992) Applications of random amplified polymorphic DNA (RAPD) in molecular ecology. Mol Ecol 1:55-63.

Kapur AP (1958) A Catalogue of the Lac Insects (Lacciferidae, Hemiptera) Lac Cess Comm, Ranchi, 47 pp.

Kapur AP (1962) The lac insect. In: Mukhopadhyay B and Muthana, MS (eds) A Monograph on Lac. Indian Lac Research Institute, Ranchi, pp 59-89.

Karam N, Guglielmino CR, Bertin S, Gomulski LM, Bonomi A, Baldacchino F, Simeone V and Malacrida AR (2007) RAPD analysis in the parasitoid wasp Psyttalia concolor reveals Mediterranean population structure and provides SCAR markers. Biol Control 47:22-27.

Kethidi DR, Roden DB, Ladd TR, Krell PJ, Retnakaran A and Feng Q (2003) Development of SCAR markers for the DNA-based detection of the Asian long-horned beetle, Anoplophora glabripennis (Motschulsky). Arch Insect Biochem Physiol 52:193-204.

Kondo T and Gullan PJ (2007) Taxonomic review of the lac insect genus Paratachardina Balachowsky (Hemiptera, Coccoidea, Kerriidae), with a revised key to genera of Kerriidae and description of two new species. Zootaxa 1617:1-41.

Lopes-Da-Silva M and Vieira LGE (2007) Analysis of the genetic diversity in Metopolophium dirhodum (Walker) (Hemiptera, Aphididae) by RAPD markers. Rev Bras Entomol 51:54-57. 
Lynch M and Milligan B (1994) Analysis of population genetic structure with RAPD markers. Mol Ecol 3:91-99.

Magaña C, Beroiz B, Hernández-Crespo P, de Oca MMA, Carnero A, Ortego F and Castañera P (2007) Population structure of the banana weevil, an introduced pest in the Canary Islands, studied by RAPD analysis. Bull Entomol Res 97:585-590.

Martins WFS, Ayres CFJ and Lucena WA (2007) Genetic diversity of Brazilian natural populations of Anthonomus grandis Boheman (Coleoptera, Curculionidae), the major cotton pest in the New World. Genet Mol Res 6:23-32.

Mishra YD and Sushil SN (2000) A new trivoltine species of Kerria Targioni-Tozzetti (Homoptera, Tachardiidae) on Scheichera oleosa (Lour.) Oken from Eastern India. Orient Insects 34:215-20.

Mishra YD, Sushil SN, Bhattacharya A and Krishan Sharma K (1998) Morphometric differences between strains of Indian lac insect, Kerria lacca (Kerrr). J Insect Sci 11:171-72.

Nagaraja GM and Nagaraju J (1995) Genome fingerprinting of the silkworm, Bombyx mori, using random arbitrary primers. Electrophoresis 16:1633-38.

Nei M (1978) Estimation of average heterozygosity and genetic distance from a small number of individuals. Genetics 89:583-590.

Pal G, Jaiswal AK and Bhattacharya A (2011) Lac statistics at a glance 2010 (Technical bulletin No. 01/2011), Indian Institute of Natural Resins and Gums, Ranchi, pp 1-24.

Prevost A and Wilkinson MJ (1999) A new system of comparing PCR primers applied to ISSR fingerprinting of potato cultivars. Theor Appl Genet 98:107-112.

Ramakishana W, Lagu MD, Gupta VS and Ranjekar PK (1994) DNA fingerprinting in rice using oligonucleotide probes specific for simple repetitive DNA sequences. Theor Appl Genet 88:402-406.

Ramani R (2002) Lac insect genetics. In: Kumar KK, Ramani R and Sharma KK (eds) Recent Advances in Lac Culture. Indian Lac Research Institute, Ranchi, pp 48-52.

Ramani R (2005) Genetics of lac insects. In: Ramamurty VV, Singh VS, Gupta GP and Paul AVN (eds) Gleanings in Entomology. IARI, New Delhi, pp 266-80.

Ramani R, Baboo B and Goswami DN (2007) Lac - An Introduction. Indian Lac Research Institute, Ranchi, 12 pp.

Reyes A and Ochando MD (1998) Use of molecular markers for detecting the geographical origin of Ceratitis capitata populations. Ann Entomol Soc Am 91:222-227.
Rohlf FJ (1998) NTSYS-PC: Numerical taxonomy and multivariate analysis system, v. 2.0. Department of Ecology and Evolution, State University of New York.

Roonwal ML (1962) Lac Hosts. In: Mukhopadhyay B and Muthana MS (eds) A Monograph on Lac, Indian Lac Research Institute, Ranchi, pp 14-58.

Saitou N and Nei M (1987) The neighbor-joining method: A new method for reconstructing phylogenetic trees. Mol Biol Evol 4:406-425.

Sarkar PC (2002) Applications of lac-Past, present and emerging trends. In: Kumar KK, Ramani R and Sharma KK (eds) Recent Advances in Lac Culture. Indian Lac Research Institute, Ranchi, pp 224-230.

Sharma AK, Mendki MJ, Tikar SN, Chandel K, Sukumaran D, Parashar BD, Vijay Veer, Agarwal OP and Prakash S (2009) Genetic variability in geographical populations of Culex quinquefasciatus Say (Diptera, Culicidae) from India based on random amplified polymorphic DNA analysis. Acta Tropica 112:71-76.

Sneath PHA and Sokal RR (1973) Numerical Taxonomy. W.H. Freeman and Company, San Francisco, pp 147-157.

Sosa-Gómez DR, Coronel N, Binnecka E, Zucchia MI and Rosado-Netoa G (2008) RAPD and mitochondrial DNA analysis of the soybean stalk weevil, Sternechus subsignatus (Coleoptera, Curculionidae) Bull Entomol Res 98:475-481.

Varshney RK (1977) Taxonomic studies of lac insects of India (Homoptera, Tachardiidae). Oriental Insects Suppl 5:1-97.

Varshney RK (1985) A review of Indian Coccids (Homoptera, Coccoidea). Oriental Insects 19:1-101.

Varshney RK (2009) Revised synoptic catalogue of the lac insects of the world (Hemiptera, Coccoidea, Tachardiidae). Bionotes 11:6-10.

Weising K, Nybom H, Wolff K and Kahl G (2005) DNA Fingerprinting in Plants: Principles, Methods and Applications. 2nd edition. CRC Press, London, 444 pp.

Welsh J and McClelland M (1990) Fingerprinting genomes using PCR with primers. Nucleic Acids Res 18:7213-7218.

Wetton JH, Carter RE, Parkin DT and Walters D (1987) Demographic study of a wild house sparrow population by DNA fingerprinting. Nature 327:147-149.

Williams JGK, Kubelik AR, Livak KJ, Rafalski JA and Tinge SV (1990) DNA polymorphisms amplified by arbitrary primers are useful as genetic markers. Nucleic Acids Res 18:65316535 .

Associate Editor: Fábio de Melo Sene

License information: This is an open-access article distributed under the terms of the Creative Commons Attribution License, which permits unrestricted use, distribution, and reproduction in any medium, provided the original work is properly cited. 